\title{
Variation and Names in the Poa secunda Complex
}

\author{
ELIZABETH ANNE KELLOGG
}

\begin{abstract}
The members of the Poa secunda complex were studied using transplant experiments, morphological studies of population samples, and various numerical taxonomic techniques including principal components analysis and discriminant analysis. The complex is shown to comprise 2 species: Poa curtifolia, serpentine endemic from central Washington, and $P$. secunda, a widespread polymorphic rangegrass. Other forms may be recognizable locally, but do not represent separate evolutionary lines. If range managers need names for these local forms, the names should be informal English names rather than Latin binomials.
\end{abstract}

Hitchcock (1950), Hitchcock et al. (1969) and Cronquist et al. (1977), give keys to the bluegrasses, but anyone who has tried to identify the grasses has found it very difficult: either the keys need improvement or the "species" are not really distinct. In the Poa secunda Presl group, there are about 40 published names; Hitchcock (1950) recognized 8 species, Hitchcock et al. (1969) recognized 11, and Marsh (1952) only 1. This study was designed to analyze the variation among the plants in the group to determine how many species could be recognized, their distinguishing characters, and the appropriate scientific names (see also Kellogg 1985). This paper summarizes the results most relevant to range scientists and managers, and then discusses the relationship of taxonomy and evolutionary biology to applied biology and management. Such a study should interest range managers and biologists for 2 reasons: First, a taxonomic study often results in name changes, important only because a standard vocabulary makes communication possible among range managers. Second, and more important, is a greater understanding of the biology of the plants.

\section{Plants and Names Applied}

Poa secunda ( $P$. sandbergii Vasey), a common bunchgrass, is most familiar as a small $(30$ to $50 \mathrm{~cm})$ caespitose plant that becomes active in early spring. After flowering it turns reddish and becomes dormant for the rest of the summer. Several other forms ( $P$. ampla Merrill, $P$. canbyi (Scribner) Piper, P. curtifolia Scribner, P. gracillima Vasey, $P$. incurva Scribner \& Williams, $P$. juncifolia Scribner, $P$. nevadensis Vasey, and $P$. scabrella (Thurber) Bentham) are closely related to $P$. secunda, and are distinguished by minor morphological characters. Some of these "species" are of interest to range managers because they are better forage grasses than typical $P$. secunda. For instance, $P$. ampla, $P$. canbyi, $P$. juncifolia, $P$. nevadensis, and $P$. scabrella all tend to have longer basal leaves, and $P$. scabrella and $P$. ampla continue growth longer into the summer.

The group is distributed over most of western North America, with disjunct populations in the Gaspé peninsula of Quebec and others in Chile. The plants occur on both moist and dry sites, from areas such as the Mojave Desert to high alpine areas of the Sierras and Rocky Mountains. The group has been called the Poa sandbergii complex, but Arnow (1981) has shown that it includes some populations in Chile, the name of which, Poa secunda, is older and takes precedence.

Although the members of the complex are commonly distinguished from other bluegrasses by the lack of a keel on the lemma, I have found this an unreliable character. It is easier to distinguish

\footnotetext{
Author is a postdoctoral fellow at the Harvard University Herbaria, 22 Divinity Avenue, Cambridge, Massachusetts 02138 .

Thanks to D.M. Henderson, under whose direction this study was started, and to C.E. Wood, Jr., under whose direction it was completed. This manuscript was greatly improved by the editorial help of S.M. Rossi, and by the comments of two anonymous reviewers.

Manuscript accepted April 18, 1985
}

the Poa secunda group by both its longer rachilla internodes ( 0.6 to $1.9 \mathrm{~mm}$ vs. $<0.5 \mathrm{~mm}$ for most other members of the genus) and its longer spikelets ( 7 to $10.5 \mathrm{~mm}$ vs. $<6 \mathrm{~mm}$ for many, but by no means all, other species). The anthers are also longer than in many other bluegrasses ( 1 to $4.2 \mathrm{~mm}$ vs. $<1 \mathrm{~mm}$ ). All members of the group are bunchgrasses with intravaginal branching; most plants have narrow panicles. The perfect flowers, although frequently pollen-sterile, are often apomictic. Long tangled cobwebby hairs, characteristic of such species as $P$. pratensis, are lacking.

\section{Methods}

In theory, many biologists believe a species is a group of "interbreeding natural populations that are reproductively isolated from other such groups"(Mayr 1963), but in practice, species are defined by morphological similarity. A plant is recognized as a red fescue because it looks like a red fescue, not because it breeds with other red fescues and produces fertile offspring. This is particularly true of bluegrasses, which produce most seeds asexually. I attempted 2,741 crosses among morphologically distinct members of the complex. I emasculated 50 florets on the pistillate parent shortly before anthesis; other nonemasculated florets were removed. The inflorescence was then enclosed in a glassine bag with an inflorescence from the staminate parent. Inflorescences remained bagged together for 3 days and the bags were shaken at regular intervals to insure that pollination had taken place. Average seed set was $23 \%$. From these crosses, only 4 hybrids were produced; the remainder were morphologically identical to the pistillate parent and were presumably apomictically formed. (I had already demonstrated widespread apomixis in microscopic studies of embryo sac development; see Kellogg 1983). The hybrids were between very different plants; e.g., one with short ligules, glaucous foliage, and long basal leaves crossed with one with long ligules, bright green foliage, and relatively short basal leaves. This suggests that, if the plants were not apomictic, they might be freely interbreeding, but such a statement is impossible to prove. The breeding criterion is untestable.

I began the study by searching for morphological units within the complex. By comparing several hundred plants transplanted to a garden in Moscow, Idaho (Table 1), with field-grown plants, I could evaluate which characters were under environmental control. I measured 60 characters from 186 plants, selected from throughout the range of the complex (Table 2). The plants were chosen in 2 ways: First, I chose one plant from each of Hitchcock's (1969) "species" for each state or province in which the "species" occurred. Second, I included small samples ( 4 to 8 plants each) of populations primarily in California and the Pacific Northwest (this second group of plants was also used for discriminant analyses). For each of the quantitative characters I calculated the mean of 5 measurements from each specimen. Data from both the transplant studies and the measurements allowed me to divide the characters into the 5 categories listed in Table 2 .

To assess variation among the offspring of self-pollinated plants, I bagged nonemasculated inflorescences of 64 plants from various field sites. Seed from these plants was planted in 1981. Because Poa secunda is pseudogamous, I had no way of telling if seed from these self-pollinated plants was self-fertilized or apomictically formed, but the results show how much variation can be produced by a single plant. Although germination was low, 2 plants (Kellogg 29 from Nez Perce, Idaho and Kellogg 122 from Morrow Co., Oregon) produced a large number of surviving offspring; I labeled these family 29 and family 122 . In the spring of 1983,14 plants of family 
Table 1. Plants grown in common garden.

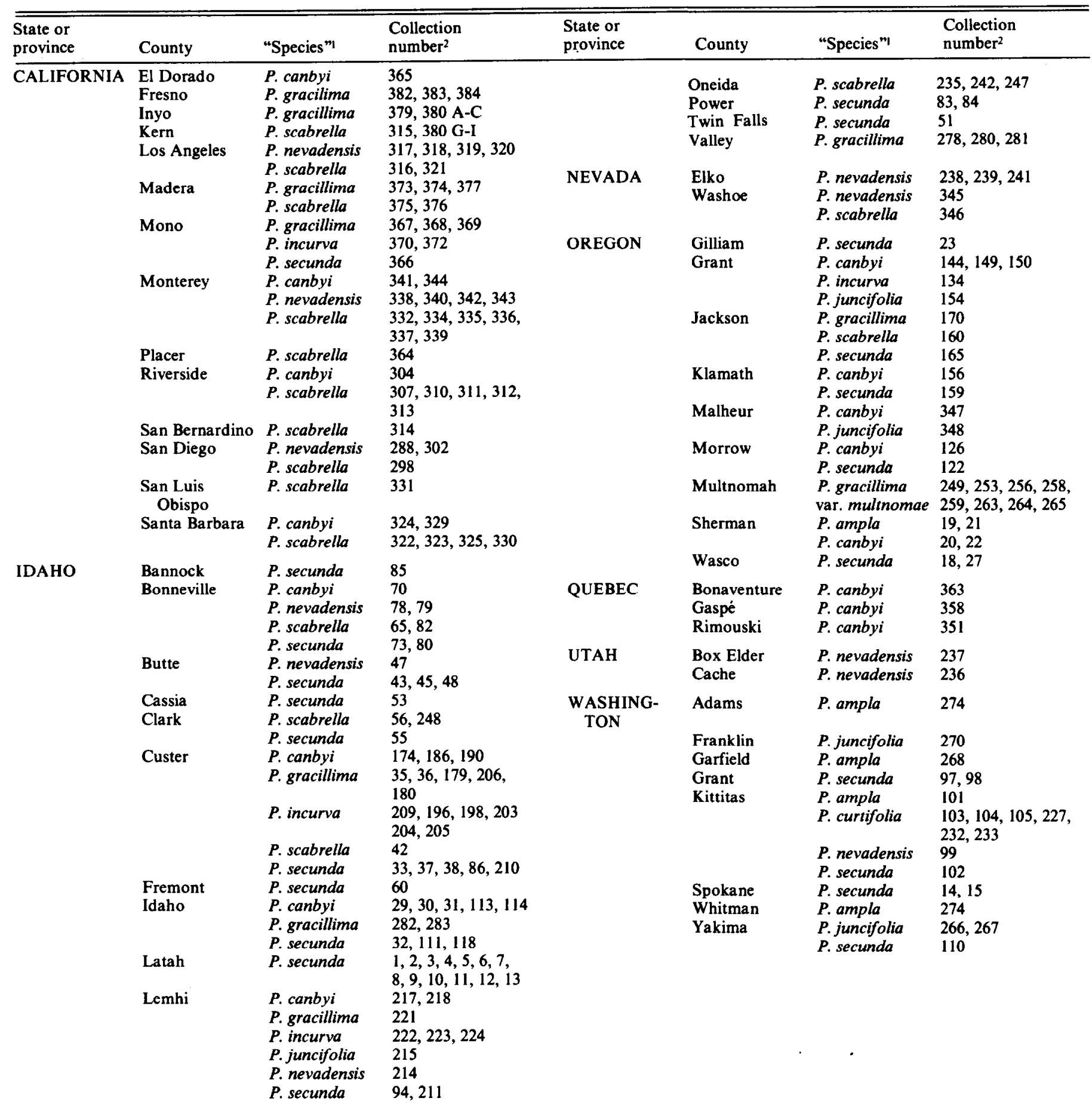

'Naming follows Hitchcock et al. (1969) insofar as possible. Many specimens cannot be reliably named, however, and determinations vary according to the key used and the taxonomist doing the identification. Names used in this table are simply to indicate sampling.

2All numbers are for Kellogg collections. One to eight representatives of each collection were transplanted to the common garden. Herbarium vouchers of numbers 1 through 283 are on deposit at ID; numbers 288 through 384 are at $\mathrm{GH}$.

29 and 17 of family 122 flowered. These I scored for the characters listed in section $V$ of Table 2.

After collecting the data, I analyzed it using univariate, bivariate, and multivariate statistical techniques. Histograms of each of the quantitative characters were plotted to see if any character divided the complex into groups. Bivariate plots between pairs of characters also were done to see if the combinations defined groups.

For multivariate analyses, I used principal components analysis (PCA) and discriminant analysis, performing several analyses on different sets of plants and characters. Both methods treat each plant as a point in multidimensional space, where each dimension is a taxonomic character. They mathematically "look at" the cloud 
Table 2. Characters studied.

\section{Invariant or nearly so}

1. habit; 2 . ligule scabrosity; 3 . ligule decurrence; 4 cilia on leaf margin; 5. leaf margin scabrosity; 6 . panicle branch scabrosity; 7 . rachis scabrosity; 8 . glume keel scabrosity; 9 cilia on glume margin; 10. glume apex shape; 11. lemma apex shape; 12 . cilia on lemma margin; 13. number of lemma nerves

II. Environmentally controlled

14. culm color; 15. leaf involution; 16. leaf glaucousness

III. Varying as much within an individual as within complex 17. number of 1st glume nerves; 18. number of 2nd glume nerves; 19. glume scabrosity next to keel; 20 . leaf midvein scabrosity

IV. Varying as much within a population as within complex

21. culm scabrosity; 22 . culm width; 23 . sheath scabrosity; 24 . abaxial leaf scabrosity; 25 . adaxial leaf scabrosity; 26 . no. panicle branches 1 st node; 27 . no. panicle branches 2 nd node; 28 . no. panicle branches 3 rd node; 29 . rachilla pubescence; 30 . tuft of hairs on callus; 31 . lemma scabrosity; 32. amount of lemma pubescence; 33. distribution lemma pubescence; 34 . length lemma hairs; 35 . amount of palea pubescence; 36. palea keel hairs or teeth; 37. palea pubescent or glabrous; 38. lodicule shape

V. Range of variation overlapping within populations

39. plant height; 40 . flag leaf height; 41 . flag leaf length; 42 . basal leaf length; 43. panicle shape; 44. panicle length; 45. distance 1st-2nd panicle node; 46 . distance 2 nd-3rd panicle node; 47 . leaf width; 48. ligule shape; 49 . ligule length; 50 . florets per spikelet; 51 . length 1 st rachilla internode; 52 . spikelet length; 53 . 1st glume length; 54 . 2nd glume length; 55. 1st glume width; 56. 2nd glume width; 57. lemma length; 58 . palea length; 59 . anther length; 60 . lodicule length

of points in hyperspace and draw an axis through its longest dimension. A second axis is placed at right angles to the first and through the next longest dimension, and so on for as many axes as there are taxonomic characters. This has the effect of representing most of the variation on the first few axes, so that, if the first 2 axes are drawn on paper and the points then plotted relative to these axes, the points will be spread out as much as possible while still retaining the same relationships to each other that they had in hyperspace. This plot of points (plants) on the new axes may show discontinuities among groups of plants. Each of the new axes is a linear combination of several taxonomic characters; these are said to be "loaded" on that axis. By examining the loadings, one can determine which characters are responsible for most of the differences among the plants. (For a more detailed, nontechnical description of factor analysis, see Gould, 1981, p. 234-255). PCA picks out very distinct groups of plants, but may blur the distinction between recognizable but fairly similar species. In other words, PCA finds a group of plants (a species) to be discrete only if it is quite distinct. 1

Discriminant analysis, on the other hand, imposes maximum discrimination among groups; it is useful in conjunction with PCA, because it is biased in the opposite direction. Thus nondiscrimination of groups convincingly shows their morphological indistinctness, but discrimination does not prove the groups are discrete. Discriminant analysis requires that plants be assigned to groups. For the groups, $I$ used 26 populations of plants primarily from California and the Pacific Northwest; each population sample consisted of 4 to 8 plants.

\footnotetext{
There are 2 other limitations to PCA. First, it tends to be strongly affected by outliers, and second, it is not designed for two- or three-state characters and will of ten weight those characters disproportionately. In this case, these 2 limitations did not affect the results. After discovering that Poa curtifolia was distinct and appeared as a set of outlying points in the analysis, I removed it from subsequent analyses. I also did a PCA with all binary and several-state characters removed. The results were not materially different from those shown in Figure 3.
}

\section{Results}

The 60 measured characters are divided into 5 categories (Table 2): I. Nonvarying or nearly so; II. Environmentally controlled; III. Varying as much within an individual as within the complex; IV. Varying as much within a population as within the complex; $V$. Ranges overlapping between populations. The 3 characters in the second category, "Environmentally controlled," have been used as key characters. Poa secunda s.s. has often been distinguished from the rest of the complex because the culm turns red on drying. However, this proved to be strongly affected by environment. Plants in the greenhouse never developed a red color; some plants that were red in the field turned green in the garden. Leaf rolling was similar; many observers have placed plants with rolled leaves in separate species from those with flat leaves (e.g., $P$. juncifolia vs. $P$. ampla). I found that leaf rolling was entirely controlled by the

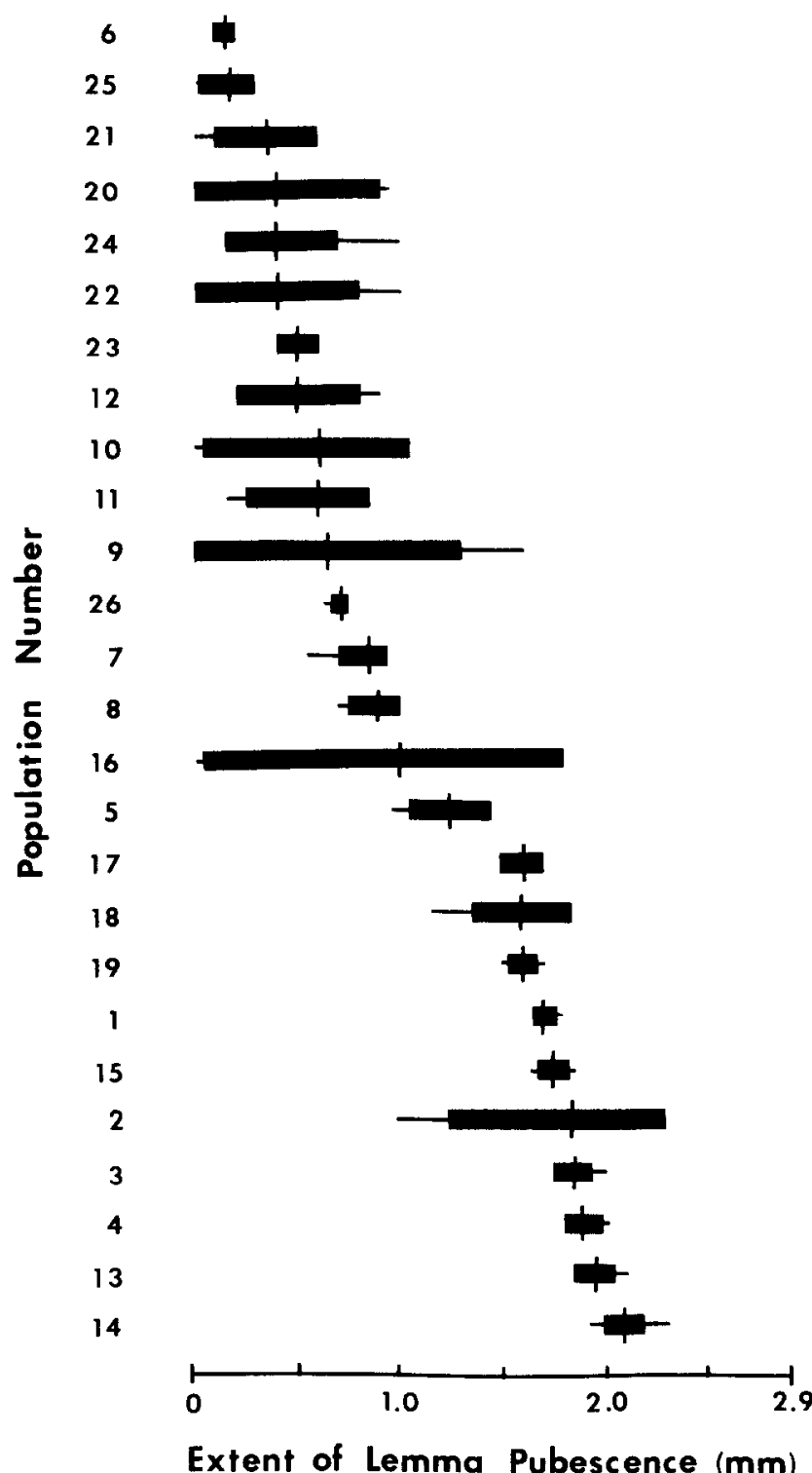

Fig. 1. Range of variation for extent of lemma pubescence compared within and among populations. Each bar represents a separate population. The narrow horizontal line shows the ranges of values for that population, the narrow vertical line the mean, and the broad horizontal bar extends one standard deviation on either side of the mean. Horizontal scale represents the full range of variation in the complex. (Figures I and 2 modified from Kellogg, 1985). 
amount of water the plant received during early growth. Glaucousness likewise varied with environment.

Obviously invariant characters cannot be used to distinguish species (Category I); characters that vary widely within the individual are also excluded (Category III), as are environmentally influenced characters (Category II). Characters varying as much within a population as within the complex may or may not be taxonomically useful; here the geographical distribution of those characters becomes important. If, for example, plants in one half of the range had scabrous lemmas, plants in the other half had glabrous ones, and there were a line of mixed populations down the middle, then 2 separate taxa would be recognized, with a hybrid zone. If, however, the mixed populations were scattered throughout the range, it would imply that such characters were polymorphic, not marking a separate evolutionary line. This is the case with the characters in the fourth category. The characters assume values apparently at random. The most interesting character, "amount of pubescence first lemma" $(\# 32)$, has been used in the past to distinguish, for example, $P$. nevadensis from $P$. scabrella. This character proved highly variable within many populations (Fig. 1). I found that no populations were completely glabrous.

Of the remaining 22 characters, none divided the complex into smaller groups. The ranges of variation overlapped from population to population (see Figure 2, plant height). Studies on the

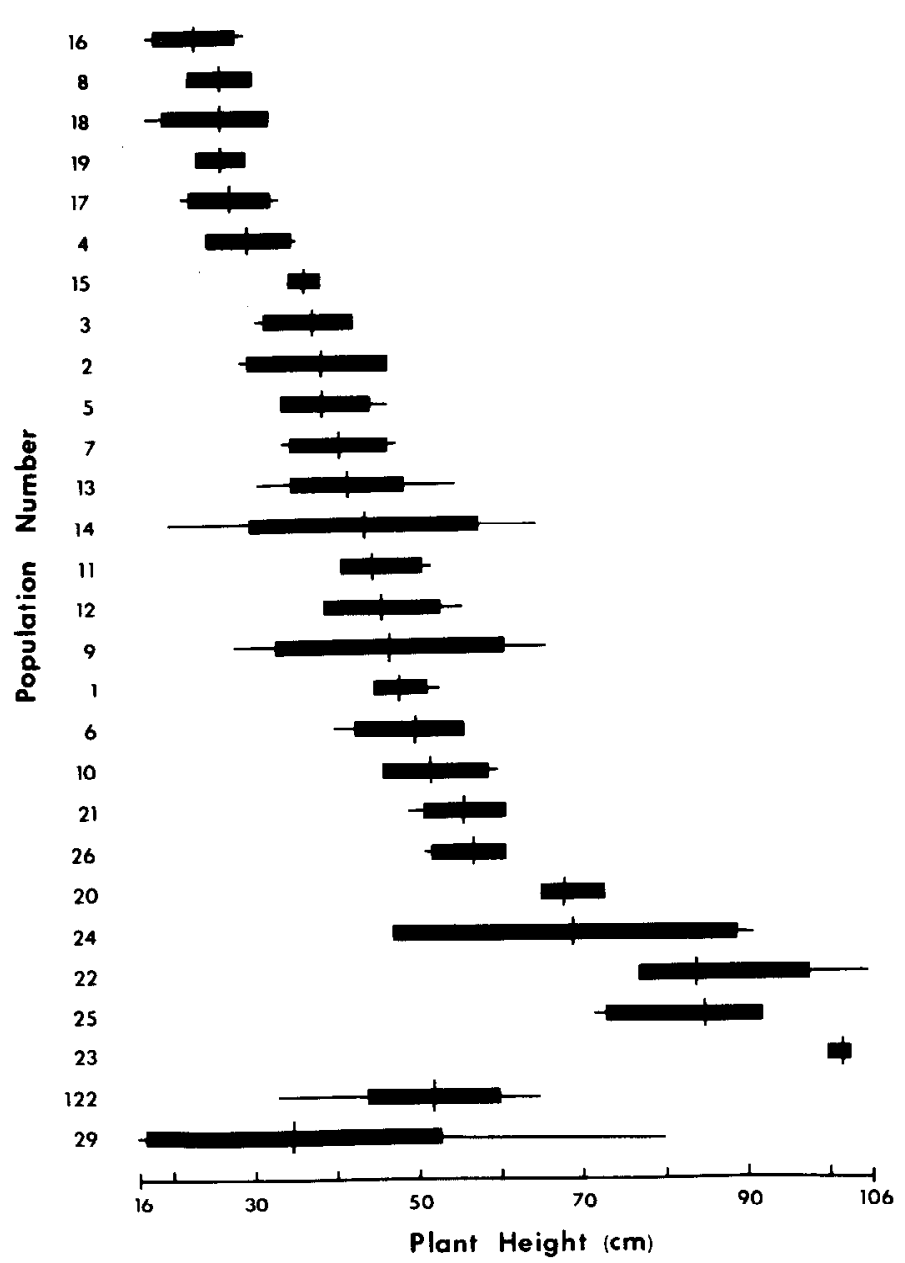

Fig. 2. Range of variation for plant height compared within and among populations. Each bar represents a separate population, except 122 and 29, which each represent the offspring of a self-pollinated plant. The narrow horizontal line shows the ranges of values for that population. the narrow vertical line the mean, and the broad horizontal bar extends one standard deviation on either side of the mean. Horizontal scale represents the full range of variation in the complex. offspring of self-pollinated plants showed equally high variation. The bottom 2 bars in Figure 2 show plant height for family 29 and family 122 ; together they show a range equalling $89 \%$ of that of the whole complex. Other characters were similar.

Histograms for all characters were unimodal and approaching normal, again showing that no single character could be used to divide the complex into species. Bivariate plots of paired combinations of characters showed no concordance between the characters.

Principal components analysis on the 9 characters used by Hitchcock (1950) showed that his taxa intergrade and that the single characters he used to define species are not concondant with each other. A PCA using all 60 characters produced the result shown in Figure 3. Poa curtifolia (diamonds) appears more or less

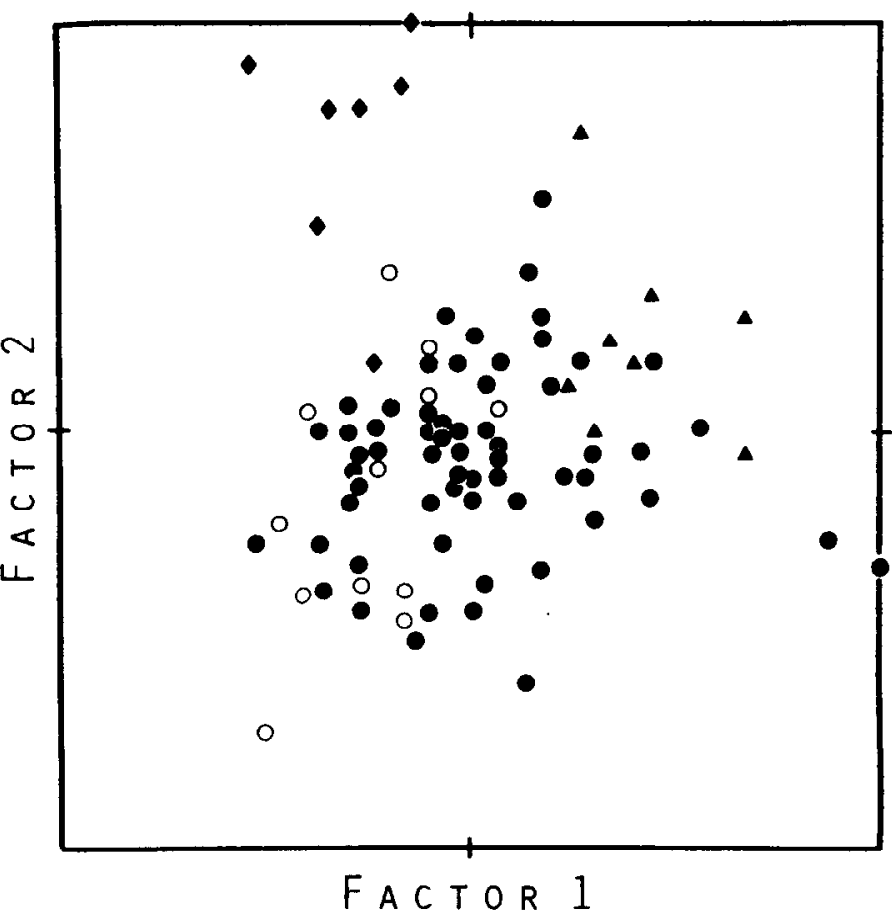

Fig. 3. Principal components analysis, factor I vs. factor 2. Each axis is 6 standard deviations long. Key to symbols: diamonds-Poa curtifolia; open circles-open-panicled plants; triangles-large plants with short ligules; solid circles-all other plants. (Figures 3 and 4 copyright 1985, Journal of the Arnold Arboretum; reproduced with permission.)

distinct from the other plants. Recall that PCA tends to blur the distinctions among taxa, so anything appearing discrete is proba bly quite recognizable in the field. The remainder of the plants did not fall into any sub-groupings. This was true even when $P$. curtifolia was removed from the analysis, when quantitative characters only were used, when the 22 characters in category $V$ were used alone, or when other combinations of factors were examined. In Figure 3, the horizontal axis represents a combination of measurements of vegetative features, and the vertical axis includes characters having to do with the size of spikelet parts. Thus $P$. curtifolia is distinguished by the combination of unusually large spikelets and florets, with short culms, leaves, and panicles.

The open circles represent plants with open panicles, known in the past as Poa gracillima; they do not form a coherent group and are not distinguished by any other characters. The triangles represent very large plants with short ligules, previously called $P$. ampla. Like the open-panicled plants, they intergrade in all respects with the rest of the complex.

Discriminant analyses amplify the results of the PCA (Fig. 4). Here Poa curtifolia is still clearly separate, and the open-panicled 


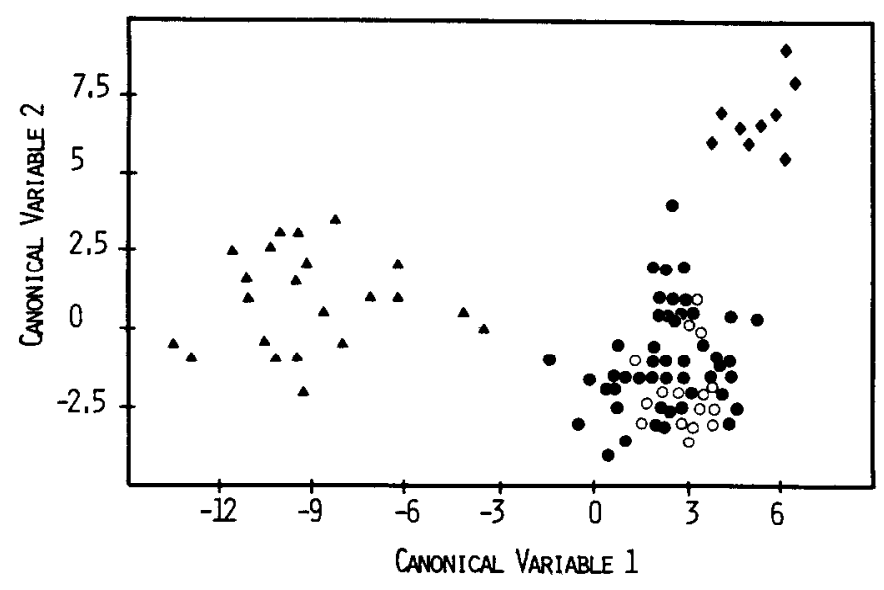

Fig. 4. Discriminant analysis. Symbols as for Figure 3.

plants still intergrade with the remainder of the complex. This analysis has maximized the distinction between groups (populations), yet the latter group remains largely indistinguishable. Therefore, the character "open panicle" is not concordant with any other characters. The implications of this will be explored more fully in the discussion.

Large plants with short ligules appear very distinct in this analysis, discriminated primarily on the basis of basal leaf length, flag leaf length, and ligule length. However, because of the bias in the analysis, this is only weak evidence for calling this group a separate species. Similarly, because of the bias in PCA, those analyses provide only weak evidence for lumping it with the rest of the complex.

The numerical analyses, therefore, have shown that Poa curtifolia is distinct from the rest of $P$. secunda, and that " $P$. gracillima" should not be considered a separate species. However, the results for " $P$. ampla" are equivocal.

Other characters are not helpful. Cross sections of leaves showed that members of the complex are variable with respect to leaf anatomy, but that the variation was heavily affected by the environment and not concordant with any aspect of morphology. Both Hitchcock et al. (1969) and Cronquist et al. (1977) have used phenology as a taxonomic character, separating species into those blooming in April, May, or June versus those blooming in July or August. I found that blooming date in the wild is correlated primarily with altitude and latitude. Plants bloom early in the growing season and then become dormant. Plants grown in the garden in Moscow, Ida., all bloomed over a single 17-day period in early May. Plants forced in the greenhouse bloomed consistently 3-4 weeks after being brought indoors. Thus, phenology is taxonomically uninformative.

Generally, members of the complex grow on neutral to strongly alkaline soils, which often have high amounts of soluble salts. Plants with open panicles and short ligules occur only on the walls of wet mossy gorges near Multnomah Falls above the Columbia River in Oregon. (These have been called Poa multnomae Piper or $P$. gracillima var. multnomae (Piper) C.L. Hitchcock or $P$. gracillima var. multnomae (Piper) C.L. Hitchcock.) Other plants with open panicles and long ligules are montane and are found most frequently in crevices in granite. Large glaucous plants are often found in apparently saline basins, although not restricted to such areas. These generalizations about ecology do not hold up to close inspection, however. To see if any edaphic characters correlated with morphology, I ran 3 multiple regressions of 7 soil characteristics ( $\mathrm{pH}$, soluble salts, $\mathrm{Ca}, \mathrm{Mg}, \mathrm{P}, \mathrm{K}$, and $\mathrm{Ca}: \mathrm{Mg}$ ) against basal leaf length, ligule length, and lemma length ( 3 characters shown by numerical taxonomy to be important in describing the total variation in the group.) $R$ values were $0.092,0.296$ and 0.127 , respectively. Edaphic factors thus do not explain the morphological variation. Poa curtifolia is the one exception; it is restricted to serpentine soils in the Wenatchee Mountains of central Washington. Other members of the $\boldsymbol{P}$. secunda complex are also found on serpentine soils, but they are not morphologically distinct.

\section{Discussion}

These analyses show that Poa curtifolia should be recognized as a distinct taxon. In addition to the characters discussed above, it can also be distinguished by its thick, almost succulent leaves often having a prominently white margin. Its chromosome number is $2 \mathrm{n}$ $=42$, with good pairing at meiosis.

I prefer to consider species, minimally, as a group of plants with sets of concordant characters. These allow us to make generalizations of the sort "Plants with character $\mathrm{X}$ will also have character Y". A hypothetical example might be, "plants with glaucous leaves will also be summer-active." The character "open-panicle" does not allow any such generalizations. Because it is not concordant with any other characters, I do not recognize "Poa gracillima" as separate from the rest of $P$. secunda. Although the open panicle may be an evolutionary novelty marking a separate lineage, it also may be a simple polymorphism or the product of a chance recombination event. Genetic "accidents" may represent incipient speciation, but they also may not. To find a nascent lineage is asking taxonomists for more prescience than they are likely to have.

This does not answer the question of whether the large plants with short ligules should be considered a separate species. Numerical analyses give equally good arguments for either recognizing the plants as a separate species or including them in Poa secunda. The very largest plants are distinct from the rest of the complex because of the relative sizes of parts. However, these unusually large plants are geographically isolated from each other, with neither distinct ecological requirements nor a distinct range. I have never found them growing in pure stands. Either they occur with other smaller members of the complex, or they occur as isolated plants in ditches or on cutbanks. They appear to be simply unusual genetic segregants that are particularly vigorous on extreme sites. This hypothesis is supported by the data on the offspring of self-pollinated plants. Some of the offspring were extremely large with respect to height, spikelet length, or some other quantitative character. Unusually large plants may thus be produced frequently by much smaller parent plants (see Figure 2 Kellogg 29). Even though they are easily recognized as extremes, they do not represent a separate lineage, and therefore should not be recognized by a separate name.

The formal, Latin-named species should be restricted to distinct recognizable lineages. A separate terminology, analogous to cultivar names in horticulture, can then be used for such forms as the strikingly large, glaucous plants with little lemma pubescence. The formally-named species are then reserved for evolutionary lineages, primarily to preserve common usage. Species names are conventionally used to reflect relationship. Plants in the same genus are thought to be more closely related than those in separate genera: plants in the same species are closer than those in separate species. I think that all the plants I include in Poa secunda are each others' closest relatives. To pull out one unit, e.g., P. ampla, because it is useful for range managers, is to obscure the primary purpose of the classification; it implies that members of $\boldsymbol{P}$. ampla are more distantly related to members of $P$. secunda than they really are. Informal English classifications are the solution in this case. $P$. ampla can be called just "big bluegrass" as it has always been, without implying anything about relationship but conveying the necessary information about forage quality.

Does this mean then that the Latin classification is irrelevant to range managers? Not at all. Even though the primary objective of the Latin classification is to reflect evolutionary relationship, it often incorporates a wealth of useful biology. For instance, in my studies of Poa secunda I have discovered that the group is biologically quite uniform and that many of the apparent field differences 
are caused by differences in the moisture level of the site. This means that, for example, if a range manager finds that his range is unproductive because of a stand of tiny $P$. secunda with $2 \mathrm{~cm}$ long basal leaves, planting " $P$. canbyi" will not help. "P. canbyi" is the same species; the differences between it and $P$. secunda are primarily an effect of environment, particularly moisture level. On the same site the tall plants of " $P$. canbyi" will be nearly as stunted as $P$. secunda.

Every range manager knows that a plant's Latin name is a guide to its literature; but the primary purpose of the Latin classification is to reflect evolution, not to reflect utility for range. The classification may, therefore, have to be augmented by an English, rangemanagers' nomenclature.

\section{Conclusions}

Among the species that have been included in the Poa secunda complex, only Poa curtifolia is distinct. The remainder ( $P$. ampla, $P$. canbyi, $P$. gracillima, $P$. juncifolia, $P$. scabrella, $P$. incurva) are all part of the single widespread species, $P$. secunda. This species is characterized by large anthers, long rachilla internodes producing a characteristically elongate spikelet, and lack of a cobweb on the lemma. Much of the morphological variation is environmentally induced. It may still be useful for range managers to have a name for some of the groups formerly called species. For instance, the large plants with long glaucous leaves, short ligules and sparse pubescence on the lemmas are distinctive in their extreme form even though all characters intergrade fully with the rest of $P$. secunda. The plants can still be recognized by their English name "big bluegrass" even though they do not constitute a separate species.
Taxonomic studies should be of interest to range managers because they represent basic studies in the biology and autecology of particular groups of plants. Name changes are only a side effect of such a study. The biological information gleaned is more important in that it provides a sound framework for any subsequent studies, whether theoretical or practical.

\section{Literature Cited}

Arnow, L.A. 1981. Poa secunda Presl versus P. sandbergii Vasey (Poaceae). Syst. Bot. 6:412-421.

Cronquist, A., A.H. Holmgren, N.H. Holmgren, J.L. Reveal, and P.K. Holmgren. 1977. Intermountain flora: vascular plants of the intermountain West, U.S.A. Vol. 6. The Monocotyledons. Columbia University Press, N.Y.

Gould, S.J. 1981. The mismeasure of man. Norton \& Co., N.Y.

Hitcheock, A.S. 1950. Manual of the grasses of the United States, ed. 2, revised by Agnes Chase. Dover Publications Inc., N.Y.

Hitcheock, C.L., A. Cronquist, M. Ownbey, and J.W. Thompson. 1969. Vascular plants of the Pacific Northwest. Part I: Vascular cryptogams, gymnosperms, and monocotyledons. Univ. of Washington Press, Seattle.

Kellogg, E.A. 1983. A biosystematic study of the Poa secunda complex. Ph.D. Thesis, Harvard University.

Kellogg, E.A. 1985. A biosystematic study of the Poa secunda complex. J. Arnold Arbor. 66:201-242.

Marsh, V.L. 1952. A taxonomic revision of the genus Poa of United States and southern Canada. Amer. Midl. Natur. 47:202-256.

Mayr, E. 1963. Populations, species, and evolution. Harvard University Press, Cambridge, Mass.
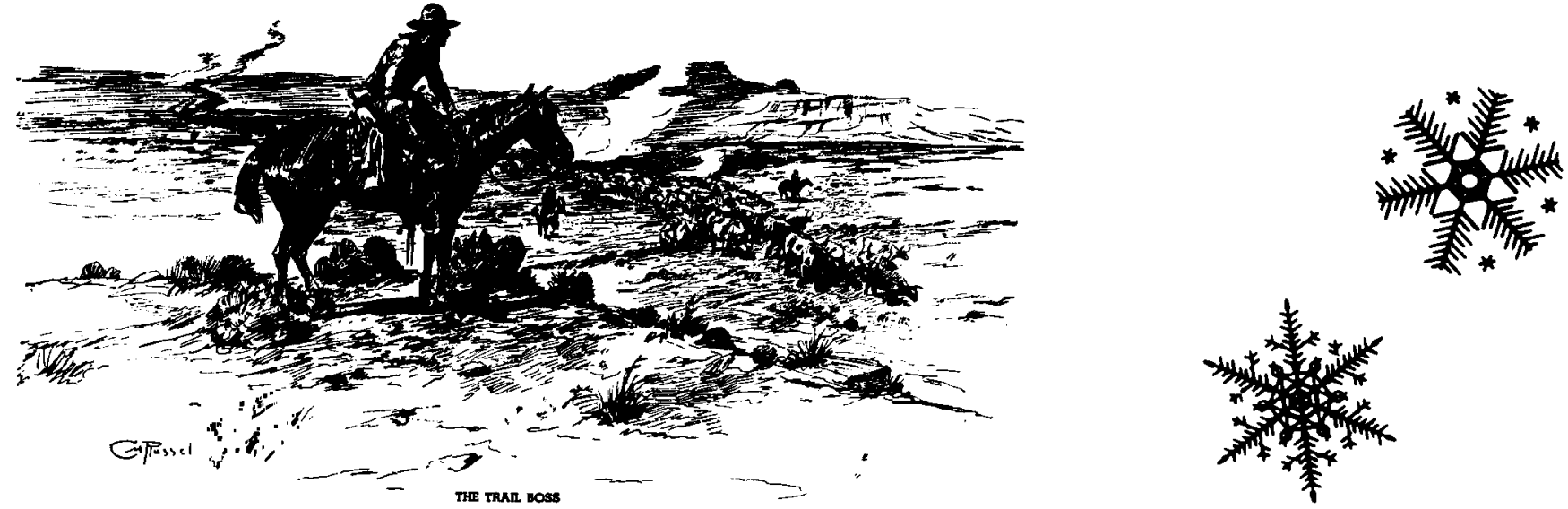

\section{This gift will make a difference.}

You don't have to worry about getting the right size because this gift fits all the range-oriented people you know.

You don't have to worry about someone duplicating your gift, because if they do, your gift just keeps coming.

You don't have to worry about wrapping it and mailing it. We do that part.

But most of all, you can rest assured that your gift can make a difference in the life of the receiver. It will open many doors to new experiences, new knowledge, and new contacts.

\section{A Membership for 1986 in the Society for Range Management}

Give a membership to a spouse, a friend, or a student you would like to help out. Use the membership form contained with each JRM or Rangelands, or write for a form to: Society for Range Management, 2760 West Fifth Avenue, Denver, Colorado 80204; or telephone (303) 571-0174 